\title{
VIKTOR FRANKL: PARA ALÉM DE SUAS MEMÓRIAS
}

\author{
Viktor Frankl: beyond their memories
}

Viktor Frankl: más allá de sus memorias

\begin{abstract}
Resumo: Esta pesquisa teve por objetivo analisar o livro de Frankl "O que não está escrito em meus livros”. Este livro é considerado o relato biográfico mais importante desse autor, ademais, torna-se relevante compreender em que medida a sua vida e a sua obra estão relacionadas. O corpus foi processado por meio do software Interface de R para Análise Multidimensionais de Textos e Questionários (IRAMUTEQ), utilizando-se a análise de similitude e nuvem de palavras. As palavras mais frequentes foram "dizer" e "fazer", as quais formaram duas estruturas de sentido. A análise revelou uma coerência existencial entre a vida e a obra do autor, e contribuiu para ampliar a compreensão do sentido da vida de Viktor Frankl.
\end{abstract}

Palavras-chave: Biografia; Psicohistória; Logoterapia

\begin{abstract}
The research aimed to analyze Frankl's book "What is not written in my books". The latter is considered the most important self-biographical material by this author, considering that it's relevant to understand to which extent his life and work are related. The research corpus has been processed through the R Interface for Multidimensional Analysis of Texts and Questionnaires (IRAMUTEQ) software through the procedure of similarity analysis and word cloud. Thus, the most frequent words were "say" and "do", which, by the same token, formed two structures of meaning. The analysis procedures revealed an existential coherence between the life and the work of the author, which helped to expand the understanding on the meaning of life of Viktor Frankl.
\end{abstract}

Keywords: Biography; Psychohistory; Logotherapy.

Resumen: Esta investigación buscó analizar el libro de Frankl “Lo que no está escrito em mis libros”. Este libro es considerado el relato biográfico más importante de ese autor, además, es relevante comprender en qué medida su vida y su obra están relacionadas. El corpus fue procesado por medio del software Interfaz de R para el Análisis Multidimensional de los Textos y cuestionários (IRAMUTEQ), utilizando análisis de similitud y nube de palabras. Las palabras más frecuentes fueron decir y hacer, las cuales formaron dos estructuras de sentido. La análisis reveló una coherencia existencial entre la vida y la obra del autor y ayudó a ampliar la comprensión del significado de la vida de Viktor Frankl. Palabras-clave: Biografia; Psicohostoria; Logoterapia.

Escrever um livro não é muito; saber viver é mais; seria muito mais escrever um livro que ensine a viver. Seria muito mais ainda viver uma vida que mereça ser relatada em um livro (Viktor Frankl, 1974/2003, p. 261).

\section{Introdução}

A logoterapia e Análise Existencial pode ser compreendida como uma abordagem da psicologia clínica alicerçada na fenomenologia, no humanismo e no existencialismo. Foi constituída por Viktor Frankl (1905-1997), psiquiatra, neurologista e professor da Universidade de Viena. Após a guerra, lança os principais pressupostos, constituindo os fundamentos de uma antropologia filosófica para uma psicoterapia centrada no sentido da existência. Para tanto, propõe tanto uma terapia específica, para aplacar o vazio existencial, quanto uma terapia não específica, por ocasião de transtornos psicogênicos (Aquino, et al., 2015).

Conforme afirmou o próprio Frankl (2010), as experiências em Auschwitz serviram como validação existencial de suas teorias. $\mathrm{Na}$ ocasião, quando se encontrava em sua "existência desnuda", sob o número 119.104, se debateu sobre o sentido do sofrimento e da morte, compreendendo a importância do sentido na vida para a sobrevivência dos prisioneiros (Frankl, 1946/2004). Os grandes temas de sua análise existencial, como morte, finitude, temporalidade e sentido da vida, foram apreendidos, sobretudo, vivencialmente, uma vez que Frankl, assim como Kierkegaard (1813-1855), foi um pensador a procura de uma verdade pela qual estava disposto a viver e também a morrer (Batalha, 1968).

Quando completou 90 anos, publicou suas memórias no livro intitulado: Was nicht in meinnen Büchern steht: Lebenserinnerunge (Frankl, 1995). Trata- 
-se de um relato autobiográfico precursor da terceira escola de psicoterapia de Viena que atravessou duas grandes guerras e ainda passou pelo período da guerra fria. Entre sofrimentos e realizações, suas posturas e ações constituíram uma história de vida pautada pela busca e realização de sentidos. Os campos de concentração se constituíram por momentos de dor e sofrimento (torturas, fome e trabalhos forçados) e, também, de luto, pelas perdas de seus entes queridos (Lukas, 1993/2011).

Esse período de sua vida, Frankl (2005/2008) enfrentou com sabedoria e adotou uma postura de um otimista trágico dizendo "sim à vida apesar de tudo”, o que lhe permitiu prosseguir a carreira profissional após a guerra. Sua obstinação em reconstruir sua obra, o trabalho como psicoterapeuta e neuropsiquiatra, o reencontro com o amor, a reconciliação com o seu passado e sua atitude de perdão, foram os aspectos salutogênicos essenciais, embora tenha contraído uma cardiopatia em decorrência do tifo exantemático.

Indubitavelmente, a história de vida deste autor está vinculada com os grandes temas do seu existencialismo, a exemplo da tríade trágica: sofrimento, culpa e morte, que vivenciou durante a Segunda Guerra, quando foi deportado de sua terra natal para campos de concentração. Como prisioneiro, foi encaminhado para os campos de trabalho forçado, sabendo que, para o sistema nazista, o valor de uma vida estava vinculado a sua utilidade. Durante o seu internamento nos campos de trabalho, questionou acerca do sentido de tantas mortes e sofrimentos e, após a guerra, constatou que quase toda a sua família estava dizimada. Nessa perspectiva, Pintos (2007, p. 09) asseverou que "O Dr. Frankl propõe uma teoria para nós. Mas, para entendê-la completamente, precisamos, não apenas de bibliografia, mas também de biografia”, por esse motivo, torna-se necessário conhecer o ser humano para apreender as suas ideias.

De forma análoga, Runyan (2006) afirma que a história da ciência psicológica pode ser mais bem compreendida por meio da psicobiografia, a despeito dos aspectos internos da ciência pura ou fatores externos ou sócio-históricos. A psicobiografia teve início com a análise de Freud acerca de Leonardo da Vince e se constitui a partir da intersecção de duas áreas distintas: a história (biografia, história oral) e a psicologia (psicologia da personalidade) (Ponterotto, Reynolds, Morel \& Cheung, 2015). Para Schultz (2005), a psicobiografia tem por meta a compreensão de pessoas e, segundo Ruyan (2003), refere-se ao estudo das histórias de vida por meio da psicologia.

De forma mais específica, a psicobiografia pode ser definida como "(...) o uso explícito da psicologia formal ou sistemática na biografia” (Ruyan, 1984, p. 202). O autor ainda defende a ampliação do campo considerando para o estudo de histórias de vida, um amplo espectro, que abarca a Psicologia do Desenvolvimento, a Psicologia Social e a Psicologia da
Personalidade. Fossatti (2010) por sua vez acresce a ideia de uma logobiografia, definindo-a como "a busca pela construção da história de vida providas de significados, tanto para aquela que narra sua trajetória quanto para o pesquisador" (p. 90).

Tendo em conta a relevância dos estudos narrativos para as ciências humanas, o presente artigo teve por objetivo realizar uma análise do livro Lo que no está escrito em mis libros (Frankl, 1995/2006). O fio condutor do presente artigo foi a seguinte pergunta: Seria possível extrair das memórias de Frankl, conforme escrito naquele livro, uma estrutura de sentido? Antes, porém, faz-se necessário apresentar algumas fontes historiográficas e dados biográficos do autor em tela.

\section{A questão do sentido na vida de Vik- tor Frankl}

Frankl nasceu em Viena, aos vinte seis dias do mês de março, em uma família de cultura judaica. Como todo judeu, herdou o seu judaísmo por via materna, por esse motivo, relata que sua mãe descendia do Rabi Shlomo Yitzhaki, que se tornou conhecido por ser um grande hermeneuta do Talmud, da torá e da Tenach (bíblia hebraica). Ademais, descendia também do Rabi Judah Löw Ben Bezaleel de Praga, que teria suas raízes na tribo de Judá, posto que o nome Löw significa leão. Compreende-se que as bases genealógicas de Frankl (1995/2006) precederam a sua busca de sentido, posto que ajudaria a situar o seu ser-no-mundo, nas palavras de Heidegger (19925/1989): "Seu próprio passado, e isso diz sempre o passado de sua 'geração', não segue, mas precede a pré-sença, antecipando-lhe os passos” (p. 48).

O seu questionamento acerca do sentido da vida surgiu na tenra idade, quando tinha quatro anos já se indagava "se a transitoriedade da vida não aniquila seu sentido" (Frankl, 1981/1990, p. 112). Posteriormente, há um período de latência até a sua adolescência, quando, aos 13 anos, interroga ao seu professor de ciências naturais acerca do sentido quando este explicava que a vida não passava de um processo de oxidação e combustão. Ademais, relata que, nesse período, tinha o hábito de meditar pela manhã acerca do sentido da vida e especificamente do sentido daquele novo dia para ele (Frankl, 1995/2006).

Quando tinha apenas 15 ou 16 anos pronunciou uma conferência sobre o sentido da vida na Universidade Popular no Grupo de Trabalho liderado por Edgar Zilsel, filósofo pioneiro da sociologia da ciência. Na ocasião Frankl (1995/2006) delineou uma das ideias centrais do seu pensamento, a de que o ser humano não deveria perguntar sobre o sentido, mas responder as demandas da vida. Dessa forma, ao contestar, torna-se responsável por sua existência. Ainda na juventude, na Associação Acadêmica 
de Psicologia Médica, teria delineado as primeiras ideias do seu pensamento: “(...) em 1926, pronunciei uma conferência e falei pela primeira vez de 'Logoterapia' ao público acadêmico. A denominação alternativa 'Análise Existencial' eu usei a partir de 1933” (Frankl, 1981/1990, p. 119). No ano de 1929, já intuía as três categorias valorativas que conferiam sentido à vida: valor vivencial, criativo e atitudinal. Seus escritos, na década de 1930, já apresentavam uma preocupação com o vazio existencial e a importância em se abordar a visão de mundo no contexto terapêutico. Essa ênfase em seu pensamento, possivelmente, foi influenciada pela crise econômica na Europa que provocou o aumento da taxa de suicídio entre os jovens naquela época, na Áustria. Mediante esse contexto, empenhou-se em desenvolver uma prática terapêutica preventiva, o que teria deixado marcas significativas em sua teoria proveniente dessa fase da proto-logoterapia (Frankl, 1981/1990).

Ainda como estudante de medicina, entra em contato com o pensamento de Max Scheler, Kal Jaspers, Martin Heidegger, Ludwig Binswanger e Martin Buber, considerando fundamental uma antropologia filosófica (Fizzotti, 2000). Em 1941, por volta dos trinta e cinco anos de idade, já tinha escrito a primeira versão do livro Ärtzliche Seelsorge, mas o período da guerra retardou a sua publicação. Durante a sua estada em campos de concentração, a tônica foi acerca do sentido do sofrimento e da morte. Após a guerra organizou o seu sistema de psicoterapia em uma intensa produção literária, que o faz encontrar o sentido de sua vida, ao ajudar outras pessoas a encontrarem sentido e valor em suas vidas (Frankl, 1981/1990).

Fizzotti (2000) aponta três aspectos relevantes na vida e obra de Viktor Frankl que influenciaram na consolidação do seu pensamento: 1) os atendimentos nos centros de aconselhamento para jovens com o intuito de prevenir o suicídio; 2) constituição gradativa de um sistema de pensamento com bases na filosofia da existência validado existencialmente nos campos de concentração e 3) elaboração de uma metodologia terapêutica fundamentada em casos clínicos, sobretudo no período pós-guerra. Em última análise, pode-se considerar que o leitmotiv de seu trabalho “(...) foi a superação do psicologismo na área da psicoterapia, que comumente está junto a um 'patologismo"' (Frankl, 1995/2006, p. 49).

Freitas (2013), ao analisar o livro autobiográfico de Frankl (1995/2006), aponta dez princípios na vida desse autor que o ajudaram a configurar uma vida saudável e com sentido: (1) ter esmero e tranquilidade, (2) não procrastinar, (3) fazer primeiro o desagradável, (4) administrar o tempo, (5) perdoar, (6) ser esperançoso, (7) perceber o positivo, (8) ter gratidão com a vida e celebrar, (9) ter compaixão e (10) ser responsável. Por conseguinte, esses princípios foram fundamentais para nortear sua obra no âmbito da psicoterapia e da saúde mental.
O Instituto de Logoterapia de Viena (http:// www.univie.ac.at/logotherapy/wp/) contabiliza 43 livros do autor. Sobre seu envelhecer, chegou a afirmar: “(...) o envelhecer não me preocupa, desde que eu possa supor que, na mesma medida que eu estou envelhecendo, estou também amadurecendo" (p. 113). Frankl morreu no dia 2 de setembro de 1997 aos noventa e dois anos de idade e foi enterrado na ala judaica do Cemitério Central de Viena. Em sua lápide não se encontra nenhuma honraria ou referência aos seus títulos, pois assim era o seu desejo: "Eu nasci Viktor Emil Frankl e vou morrer sendo Viktor Emil Frankl" (conforme citado por Pintos, 2007).

\section{Fontes historiográficas da vida de Vik- tor Frankl}

Atualmente encontram-se disponíveis três fontes primárias para o estudo da história de vida de Viktor Frankl, são elas: El hombre em busca de sentido (Frankl, 1946/2004), Lo que no está escrito em mis libros (1995/2006) e Lettere di um sopravissuto: cio che mi ha salvato dal lager (Frankl, 2005/2008). A primeira obra trata-se de um relato biográfico da experiência dos campos de concentração. De forma geral, o autor descreve as reações psicológicas dos prisioneiros desde a internação até a fase da libertação. Relata, fundamentalmente, os posicionamentos existenciais dos prisioneiros (Aquino, 2012). Frankl, aos quarenta anos de idade, com o auxílio de um gravador, ditou em nove dias as memórias de suas vivências dessa fase de sua vida antes de surgir a sua versão impressa desse livro.

A segunda obra é mais abrangente, pois foi redigida quando tinha noventas anos e abarca todas as suas memórias mais significativas, desde a infância até o seu envelhecimento. Por fim, a última fonte são compilações de cartas que o autor escreve no pós-guerra de 1945 a 1949 endereçadas a irmã, que migrou para Austrália, a outros parentes e amigos. É uma obra post mortem que desvela o estado psíquico do autor, bem como o cotidiano de um sobrevivente em busca de reconstruir sua existência após a sua libertação, que ocorreu em 27 de abril de 1945, data que considerava como o seu segundo aniversário (Frankl, 2005/2008).

A título de exemplificar a sua vida após a guerra, apresenta-se, a seguir, um fragmento de uma carta datada de 24 de janeiro de 1946 enviada para a sua irmã, Stella Bondy, que residia na Austrália:

Brevemente será impresso dois livros meu: um volumoso livro de psicoterapia (Ärtzliche Seelsorge) e outro pequeno (Ein Psycholog erlebt das Konzentrationslager). Esse segundo texto - que é muito autobiográfico - O farei sair na Áustria apenas com o meu número de prisioneiro. $\mathrm{O}$ outro me servirá também como tese de habilitação a docência (Frankl, 2005/2008, p. 67). 
Em 11 de agosto do mesmo ano, Frankl escreve outra carta para a sua irmã e comenta sobre o sucesso desses livros em sua pátria. O livro Ein Psycholog erlebt das Konzentrationslager teve uma resenha publicada no jornal austríaco Arbeiter Zeitung, enquanto que seu livro Ärtzliche Seelsorge já se esgotara em sua segunda edição (Frankl, 2005/2008).

As fontes se constituem em fragmentos complementares que auxiliam na compreensão da história de vida de Viktor Frankl, entretanto, podem-se encontrar narrativas diferentes sobre um mesmo fato. Por exemplo, acerca do campo de concentração, em sua primeira versão, o autor comenta que, ao chegar a Auschwitz, um comandante, identificado como doutor M, o enviou para fila da direita, ou seja, para aquele contingente que iria ser encaminhado para o trabalho (Frankl, 1946/2004). Já em uma segunda versão, além de identificar quem seria o referido doutor M, afirma ter sido encaminhado para a fila da esquerda, aquela que levariam os presos, que não se encontravam aptos para o trabalho, para a câmara de gás. Assevera ainda que teria dado a volta por trás do médico nazista Mengele, que estava selecionando os recém-chegados, e ter-se juntado aos demais prisioneiros que escaparam a primeira seleção. O autor assegura que nunca tinha explanado sobre isso antes por não ter a nitidez em suas memórias de que esse fato teria ocorrido ou não (Frankl, 1995/2006).

\section{Procedimentos Metodológicos}

O presente estudo pode ser classificado como um estudo narrativo por se debruçar acerca de uma autobiografia (Creswell, 1998). O corpus da análise se constituiu a partir do autorrelato produzido por Frankl (1995/2006) no seu livro intitulado Lo que no está escrito em mis libros, no original Was nict in meinen Büchern steht: Lebenserinnerungen (Frankl, 1995). A escolha da versão em espanhol decorreu do fato de que, de forma geral, as traduções das suas obras nessa língua se apresentam bem mais precisas quando comparadas com a versão em português. Outro fator decisivo para a escolha da tradução em espanhol foi o seu acesso digitalizado (online), uma condição necessária para análise computacional.

O software Interface de R para Análises Multidimensionais de Textos e Questionários (IRAMUTEQ), desenvolvido por Ratinaud (2009), possibilitou análise de coocorrências de palavras nos segmentos de textos do corpus textual em foco. Dessa forma, foi realizada análises lexicais com a finalidade de identificar estruturas de sentidos. Compreende-se estrutura de sentido conforme definiu Abbagnano (2006): "Esse movimento próprio do ato existencial autêntico, essa fusão de uma situação futura que se apresenta como indeterminada em sua possibilidade, mas que, contudo, deve ser, com uma situação inicial, pode ser chamada de estrutura” (p. 32).
Para efeito da análise, as palavras do corpus foram submetidas à técnica de lematização a fim de identificar as palavras com base em sua raiz por meio do seu significado lexical. Assim, inicialmente, foi extraída uma nuvem de palavras para identificar os vocábulos mais frequentes evocadas no corpus. Em seguida, realizou-se uma análise de similitude que permitiu encontrar um conjunto de significação derivado das conexidades de palavras evocadas no texto em questão. Os vocábulos foram representados em forma de grafos a partir das suas relações no corpus textual (Marchand \& Ratinaud, 2012; Pereira, 2001).

\section{Resultados e Discussão}

Inicialmente o software IRAMUTEQ gerou 758 segmentos de textos a partir do corpus em questão. Por meio do método de nuvem de palavras, constatou-se que o verbo decir (dizer), que se repetiu 135 vezes no corpus, foi o que mais se destacou, seguido do verbo hacer (fazer) que apareceu 111 vezes, como pode ser observado na Figura 1. Como exemplo de um seguimento de texto que aparece o verbo decir (sagen, em alemão), encontra-se: mientras la gente a su alrededor estaba al borde del pânico él lês iba diciendo mantén tu serenidad y alegria dios siempre manda su ayuda ló decía soriendo. Em sua versão original, encontra-se: Während die Leute einer Panik nahe waren, sagte er ein paarmal zu ihnen: "immer nur heiter, Gott hilft schon weiter” (Frankl, 1995, p. 05). Já em relação ao verbo hacer (machen, em alemão), verifica-se: hacer las cosas más pequeñas con el mismo esmero que las más grandes y a la vez las más grandes con la misma calma que las más pequeñas. No original em alemão, encontra-se: Iche mache die kleinsten Dinge mit derselben Gründlichkeint wie die größten und dafür die größten mit der derselben Ruhe wie kleinsten (Frankl, 1995, p. 13-14).

$\mathrm{O}$ primeiro segmento de texto refere-se às palavras do seu pai quando estavam caminhando para a estação de trem que os levariam para o gueto de Theresienstadt, enquanto o segundo refere-se as suas atividades como conferencista e professor. De forma geral, considera-se que esses dois verbos foram constitutivos para compreender o sentido da existência de Viktor Frankl, quando o mesmo desvela suas posturas e ações no mundo em suas memórias autobiográficas.

Constata-se que as palavras campo e concentração não tiveram tanto destaque na nuvem de palavras. Embora a Segunda Guerra Mundial tenha sido uma vivência de dor e sofrimento, a mesma se ofusca perante a riqueza semântica de sua narrativa existencial. 


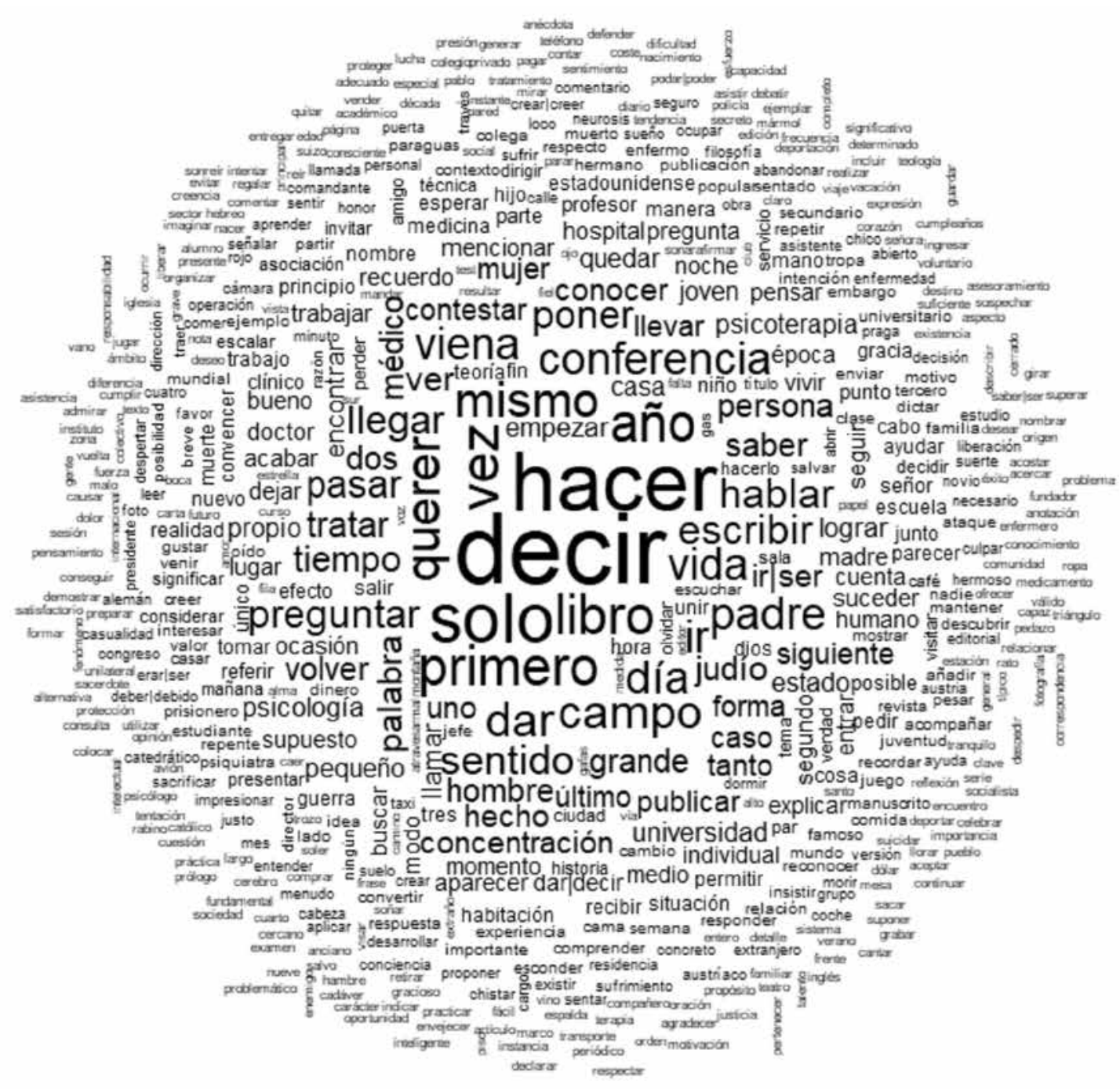

Figura 1. Nuvem de palavras obtida a partir do corpus textual das memórias autobiográficas de Viktor Frankl

Conforme a árvore de coocorrência (Figura 2), dois grandes núcleos de sentidos na biografia de Frankl emergem em torno dos verbos fazer e dizer. O primeiro se conecta com palavras que se referem as suas atividades como médico e escritor. Desse mesmo núcleo deriva-se outro conjunto de palavras em torno do termo conferência, que foi também uma faceta importante na vida do autor em foco. O segundo núcleo de sentido se forma a partir do verbo "dizer", que se associa com os termos: querer, palavra, perguntar, contestar, psicoterapia, tratar, ver, conhecer. O sentido se desvela por meio da palavra, o verbo dizer está relacionado na própria afirmação da existencialidade do ser humano, emergindo da sua própria vontade de sentido. Assim, desse núcleo, emerge uma ramificação circunscrita ao redor da palavra vida (sentido, forma, humano, buscar, pessoa) que se deriva, por sua vez, para outra estrutura em torno da palavra primeiro, na qual descreve as experiências vividas do biografado na cidade de Viena.

Por fim, o verbo dizer, também se conectou com a palavra "sozinho", o que possivelmente está relacionado com os seus solilóquios e diálogos internos. Também esse mesmo verbo se associa com campo e mesmo. Retomando em suas memórias as experiências nos pequenos campos de trabalho forçado durante a guerra, bem como a sua contestação da psicologia de sua época.

Segundo Lukas (1999), as palavras-chave evocadas no discurso de uma pessoa são fundamentais para descoberta de "pegadas" que podem trazer à luz sentidos ocultos. Dessa forma, a análise de similitude pode desvelar as palavras mais evocadas em uma biografia, o que permite identificar núcleos de sentidos por meio de suas respectivas conectividades com outras palavras. Nesta mesma direção, Bruzzone (2011) considerou que por meio da escrita autobiográfica se pode compreender os sentidos latentes que permanecem ocultos para quem escreve.

Conforme a árvore de coocorrência (Figura 2), os dois verbos, decir e hacer, estão fortemente associados entre si, demonstrando a coerência entre a vida e o seu pensamento, o que se pode considerar como uma característica de sua congruência. Sobre isto, Pintos (2007) assevera que a vida e a obra de Frankl se completam em uma sequência de fatos, o constituindo como um ser 
humano congruente. Como congruência o autor compreende: "esse tipo de coerência íntima, própria, aquela sintonia especial entre nosso ser-atual, nosso sentir e crer, e nosso dever-ser" (p. 277). Segundo McAdams (2006), as pessoas encontram sentidos em suas vidas quando reconstroem o passado, pois esse fornece um senso de identidade e coerência em suas histórias de vida. Ademais, o sentido do ser deve ser apreendido no horizonte temporal e histórico.

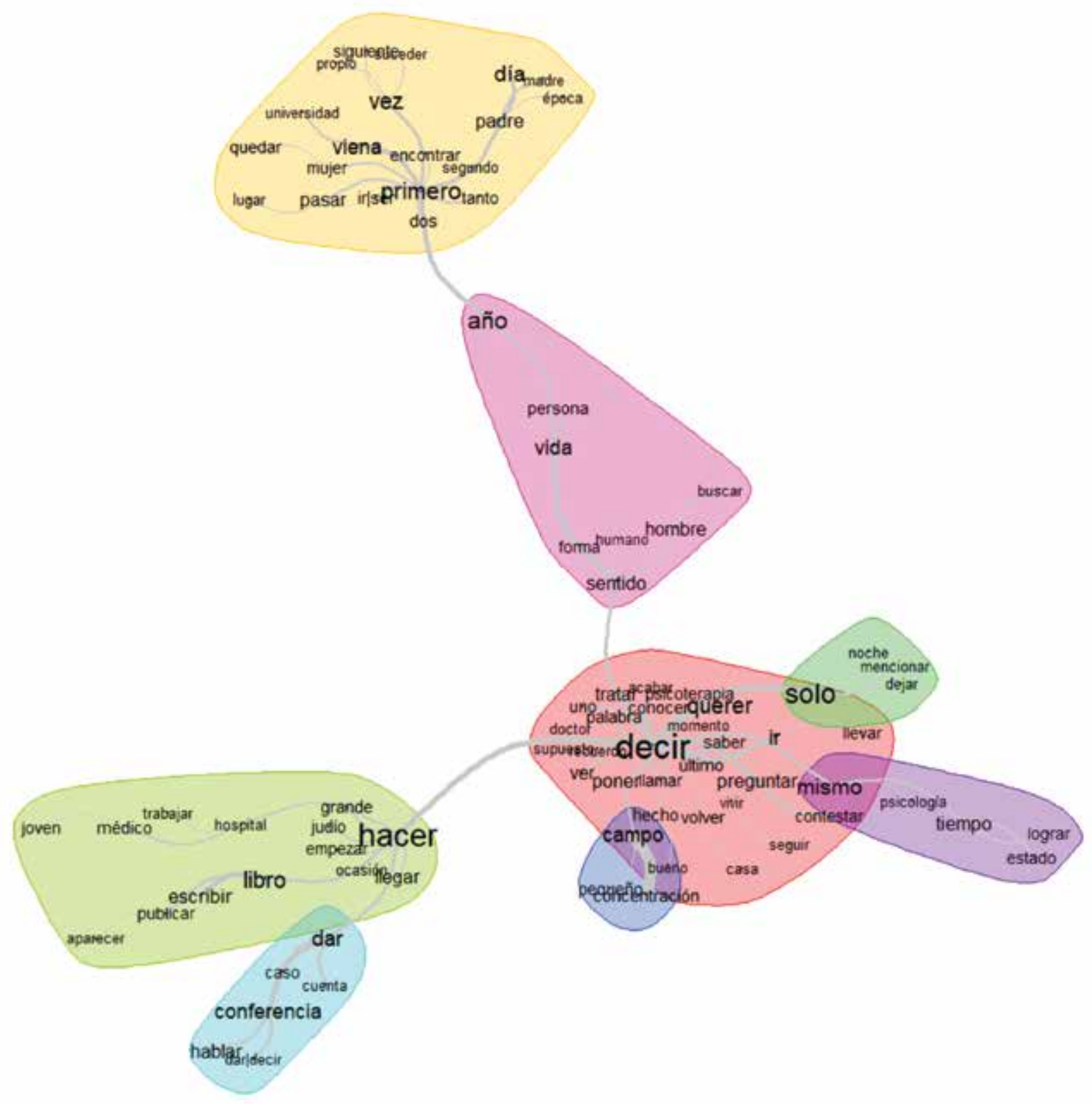

Figura 2. Árvore de coocorrência obtida a partir do corpus textual das memórias autobiográficas de Viktor Frankl

De certa forma, uma biografia se constitui na medida em que o passado se presentifica na consciência. Conforme pensa Heidegger (1925/1989) "A pré-sença 'é' sempre o seu passado no modo do seu ser, o que significa, grosso modo, que ela sempre 'acontece' a partir do seu futuro" (p. 48). Dessa forma, os grafos, que podem representar a existência de Viktor Frankl, ou seja, o seu próprio passado, o seu ser-assim, o que ele decidiu que acontecesse a partir do ato de fazer-se a si mesmo mediante as suas possibilidades no vir-a-ser. Na perspectiva da logoterapia (Frankl, 1978/1989), o passado seria a dimensão mais segura, posto que tudo o que o ser humano realizou permanece de forma perene, já que nada ou ninguém pode retirar aquilo que fluiu das possibilidades (futuro) para a realidade (passado). Nesse caso, a árvore de coocorrência representaria sinteticamente a realidade existencial do "ser-no-mundo" de Viktor Frankl.

Segundo Abbagnano (2006), o ato existencial unifica o passado e o futuro, fundamenta a existência na medida em que se decide realisar o dever ser. Dessa forma, em uma perspectiva existencial o agir no mundo significa escolher mediante as possibilidades no vir-a-ser, por essa razão "não respondemos a vida com palavras, senão com ações. Isso sim, ações que 
nos fazem responsáveis" (Frankl, 1982/2000, p. 58). Segundo a análise existencial, a biografia é a explicação temporal do ser humano (Frankl, 1987/1990), por conseguinte, essa mesma premissa poderia ser utilizada para clarificar a autobiografia em destaque que, inequivocamente, foi uma personalidade que encontrou sentidos no desdobramento de sua própria existência, constituindo, por meio da temporalidade, sua própria unicidade e autenticidade.

Pode-se apreender nas análises efetuadas do corpus aquilo que Buber (2006) já sinalizava: que cada ser é chamado para realizar sua particularidade, em suas palavras, "essa tarefa principal é a concretização única e específica de suas potencialidades, e não a repetição de algo que um outro, ainda que seja maior, já tenha feito" (p. 17). Assim, considera-se que tanto a nuvem de palavra quanto a análise de similitude representam o modo humano singular de Viktor Frankl, ou seja, o seu "ser assim" manifesto por meio de sua autobiografia.

\section{Considerações finais}

O objetivo do presente manuscrito foi realizar uma análise do livro Lo que no está escrito em mis libros. De forma mais específica, tentou responder o seguinte questionamento: Seria possível compreender nas entrelinhas desse livro uma estrutura de sentido? Por meio da lexicografia básica, nuvem de palavras e análise de similitude, foi possível identificar o vocabulário mais frequente na narrativa de vida de Viktor Frankl bem como estruturas de sentidos na sua autobiografia. Pôde-se constatar que a vida e a obra do autor se completam como duas faces de uma moeda, posto que suas preocupações humanas foram se constituindo em seu próprio pensamento antropológico. A árvore resultante da análise permitiu a identificação das coocorrências entre as palavras e indicações da conexidade entre os verbos: $d e-$ cir (dizer) e hacer (Fazer), o que permite identificar duas estruturas de sentidos que mais se destacam na autobiografia de Viktor Frankl

Destaca-se também a inovação metodológica proposta nesse artigo para fins de análises de autobiografias. As ferramentas disponíveis no software IRAMUTEQ, como análise de similitude e nuvem de palavras, podem ser úteis para os estudos narrativos, contribuindo para a identificação de estruturas de sentidos latentes nos corpus textuais de autobiografias. Nesse caso, seria mais pertinente denominar essa análise de logobiografia (Fossatti, 2010) tendo em conta que se trata mais de uma análise existencial do que uma análise psicológica da narrativa de vida.

Como limitação do estudo, considera-se que a presente análise não se deteve nos possíveis aspectos socioculturais que poderiam ter influenciado o pensamento de Viktor Frankl, como sugere Wertheimer (1998) para pesquisas no âmbito da História da Psicologia, mas se debruçou tão somente nos aspectos idiossincráticos da vida desse autor, os quais poderiam ter contribuído significativamente para a constituição da Logoterapia e sua Análise Existencial. Para suprir essa lacuna, sugere-se que futuros estudos possam ampliar essa compreensão acrescendo dados acerca da influência do Zeitgest na obra do referido autor como o fez Pareja Herrera (2007).

Por fim, recomenda-se, para fins de identificação de possíveis estruturas de sentidos, que posteriores estudos possam utilizar dessa mesma proposta metodológica para fins de análises biográficas, sejam em relatos autobiográficos de personalidades históricas, sejam em contexto clínico com narrativas de histórias de vida produzidas por consulentes. Com o intuito de despertar a responsabilidade existencial, conforme expresso na epígrafe desse artigo, pode-se propor o seguinte imperativo categórico: viva agora uma vida que seja digna de ser retratada em um livro, onde o biógrafo e o biografado se fundem em uma só pessoa.

\section{Referências}

Abbagnano, N. (2006). Introdução ao existencialismo (M. Macionilo, Trad.) São Paulo: Martins Fontes.

Aquino, T. A. A. (2012) Análise da narrativa de Viktor Frankl acerca da experiência dos prisioneiros nos campos de concentração. Revista da Abordagem Gestáltica, 18, 206-215.

Aquino, T. A. A., Veras, A. S., Braga, D. O., Vasconcelos, S. X. P., \& Bandeira, L. (2015). Logoterapia no contexto da psicologia: Reflexões acerca da análise existencial de Viktor Frankl como uma modalidade de psicoterapia. Revista Logos e Existência, 4, 45-65.

Batalha, W. de S. C. (1968). A filosofia e a crise do homem: panorama da filosofia de Descartes a Sartre. São Paulo: Editora Revista dos Tribunais.

Buber, M. (2006). O caminho do homem segundo o ensinamento chassídico (C. Abeling, Trad.). São Paulo: É realizações. (Originalmente publicado em 1948).

Bruzzone, D. (2011). Afinar la consciencia: educación y búsqueda de sentido a partir de Viktor E. Frankl. Buenos Aires: San Pablo.

Creswell, J. (1998). Qualitative Inquiry and Research Design: Choosing among Five Traditions. Thousand Oaks, CA: Sage Publications.

Fizzotti, E. (2000). Invito Allá Leitura degli scritti Del Giovane Frankl. Em: V. E. F. (Org). Le radici della logoterapia: scritti giovanili 1923-1942 (pp. 5-15). Roma: Libreria Ateneo Salesiano. 
Fossatti, P. (2010). Por uma logobiografia: possíveis contribuições de Viktor E. Frankl para uma história de vida com sentido. Em: M. H. M. B. Habrão (Org.). (Auto)biografia e formação humana, (pp. 89-108). Porto Alegre: EDPUCRS.

Frankl, V. E. (1989). Um sentido para a vida: Psicoterapia e humanismo (H. S. Lapenta, Trad.) Aparecida, SP: Editora Santuário (Originalmente publicado em 1978).

Frankl, V. E. (1990). A questão do sentido em psicoterapia (J. Mitre, Trad.). Campinas, SP: Papirus (Originalmente publicado em 1981).

Frankl, V. E. (1990b). Logoterapia e análisis existencial: Textos de cinco décadas. (J. A. P Diez, R. Wenzel \& I. Arias, Trads.) Barcelona: Herder (Originalmente publicado em 1987).

Frankl, V. E. (1995). Was nicht in meinnen Büchern steht. Lebenserinnerunge. Munique: Quintessez

Frankl, V. E. (2000), En el pricipio era el sentido: Reflexiones en torno al ser humano. (H. P. Minguijón, Trad.) Barcelona: Paidos (Originalmente publicado em 1982).

Frankl, V. E. (2003). El hombre doliente: fundamentos antropológicos de La psicoterapia. Barcelona: Herder (Originalmente publicado em 1974).

Frankl, V. E. (2004). El hombre em busca de sentido (C. Kopplhuber, Trad.). Barcelona: Herder (Originalmente publicado em 1946).

Frankl, V. E. (2006). Lo que no está escrito em mis libros. (I. Ostrowsky, Trad.) Buenos Aires: San Pablo (Originalmente publicado em 1995).

Frankl, V. E. (2008). Lettere di um sopravissuto: cio che mi ha salvato dal lager. (R. Pentangelo, Trad.) Roma: Rubbettino (Originalmente publicado em 2005).

Frankl, V. E. (2010). Em busca de sentido: um psicólogo no campo de concentração (W. O Schlupp \& C. C. Aveline, Trads.). São Leopoldo: Sinodal; Petrópolis: Vozes (Originalmente publicado em 1945).

Freitas, M. L. S. (2013). Afrontamento e superação de crises: Contribuições da logoterapia. Ribeirão Preto, SP: IECVF.

Heidegger, M. (1989). Ser e tempo (M de S. Cavalcanti, Trad.). Petrópolis, RJ: Vozes (Originalmente publicado em 1927).

Lukas, E. (1999). "Key words” as guarantee against the imposition of values by the therapist. The International Forum for Logotherapy, 22, 01-07.
Lukas, E. (2011). Uma vida fascinante: En la tensión entre ser y deber ser. (I. Ostrowsky, Trad.) Buenos Aires: San Pablo (Originalmente publicado em 1993).

Mcadams, D. P. (2006) The Problem of Narrative Coherence. Journal of Constructivist Psychology, 19, 109-125.

Marchand, P., \& Ratinaud, P. (2012). Lanalyse de similitude appliqueé aux corpus textueles: les primaires socialistes pour l'election présidentielle française. Em Actes des 11eme Journées internationales d'Analyse statistique des Données Textuelles. JADT (pp. 687-699).

Pareja Herrera, L. G. (2007). El mundo y el tiempo de Viktor Frankl. Buenos Aires: San Pablo.

Pereira, C. (2001). Análise de dados qualitativos aplicados às representações sociais. Psicologia, 15, 177-204.

Pintos, C. G. (2007). Um hombre llamado Viktor. Buenos Aires: San Pablo.

Ponterotto, J. G., Reynolds, J. D., Morel, \& Cheung, L. (2015). Psychobiography Training in Psychology in North America: Mapping the Field and Charting a Course. Europe's Journal of Psychology, 11, 459-475.

Ratinaud, P. (2009). IRAMUTEQ: Interface de $R$ pour les Analyses Multidimensionnelles de Textes et de Questionnaires [Computer software]. Retrieved from http://www.iramuteq.org

Ruyan, W. M. (1984). Life histories and psychobiography: Explorations in Theory and Methodo. New York: Oxford University Press.

Ruyan, W. M. (2003). From the Study of Lives and Psychohistory to Historicizing Psychology: A Conceptual Journey. AnnPsy, 31, 119-132.

Runyan, W. M. (2006). Psychobiography and the Psychology of Science: Understanding Relations Between the Life and Work of Individual Psychologists. Review of General Psychology, 10, 147-162.

Schultz, W. T. (2005). Introducing Pysichobiography. Em Schultz, W. T (Org.). Handbook of Psychobiography (pp. 3-18). New York: Oxford University Press.

Wertheimer, M. (1998). Pesquisa histórica - Por quê? Em J. Brozenk, \& Massimi, M. (Orgs). Historiografia as Psicologia Moderna (pp. 21-41). São Paulo: Unimarco \& Loyola. 
Thiago Antonio Avellar de Aquino (0000-00023903-8378) possui graduação em Psicologia pela Universidade Federal da Paraíba, Mestrado e Doutorado em Psicologia (Psicologia Social) pela Universidade Federal da Paraíba (2009). Atualmente é professor Associado da Universidade Federal da Paraíba do Centro de Educação; líder do grupo LAPLAE: Laboratório de Pesquisa em Logoterapia e Análise Existencial (Cadastrado no Diretório de Grupos de pesquisa do CNPq); membro do Grupo de Trabalho (GT) Psicologia e Religião da ANPEPP. Endereço Institucional: Cidade Universitária, s/n - Castelo Branco III, João Pessoa - PB, CEP 58051-085. Email: logosvitae@ hotmail.com

Recebido em 15.06.2018

Primeira Decisão Editorial em: 23.04.2019

Aceito em: 27.05.2019 